\title{
Numerical Modelling of Trajectory of High Altitude
}

\section{Missions}

\author{
Nicolae Jula ${ }^{1}$ and Florin Mingireanu ${ }^{2}$ \\ 1. Military Technical Academy, Bd. George Cosbuc, Nr. 81-83, Sector 5, Bucharest 050141, Romania \\ 2. ROSA (Romanian Space Agency), Str. Mendeleev, Nr. 21-25, Sector 1, Bucharest 010362, Romania
}

\begin{abstract}
This paper shows several stratospheric flights performed with weather balloons both in Romania and Australia. A typical 6 DOF (degrees of freedom) model is presented for the payload in order to allow a future implementation of controlled payload recovery through the usage of a steerable parafoil. Also an ascent rate calculation model is presented that takes into account a standard US 1976 atmosphere model as well as the thermodynamics of the lifting gas inside the weather balloon. It is shown the typical payload used as well as the APRS (automatic packet reporting system) communication package used for tracking and telemetry real-time as well as the photo and video equipment used for flight imaging. Altitude and trajectory are presented as functions of time and discussion is done regarding the best GPS (global position system) installation position in order to ensure GPS coverage data for most of the flight, including the burst. Various flight dynamics characteristics are described including the ascent and descent rates as well as a detailed description on how to achieve a desired ascent rate. Future aerosol detection mission is proposed in the framework of the next generation of satellites aimed at actively detecting aerosol pollution in the atmosphere. High altitude balloon platforms are proposed to provide calibration and validation of satellite data in various regions of interest worldwide.
\end{abstract}

Key words: Balloon, high, altitude, weather, ascent, descent, platform, satellite.

\section{Notations}

\begin{tabular}{|c|c|}
\hline $\mathrm{u}, \mathrm{v}, \mathrm{w}$ & $\begin{array}{l}\text { velocity components in body frame } \\
\text { [meters/second] }\end{array}$ \\
\hline$\theta$ & pitch angle [radians] \\
\hline$\varphi$ & roll angle [radians] \\
\hline$\psi$ & yaw angle [radians] \\
\hline$I_{1}$ & axial moment of inertia $\left[\mathrm{kg} \cdot \mathrm{m}^{2}\right]$ \\
\hline$I_{2}=I_{3}$ & lateral moments of inertia $\left[\mathrm{kg} \cdot \mathrm{m}^{2}\right]$ \\
\hline$q_{0}, q_{1}, q_{2}, q_{3}$ & $\begin{array}{l}\text { quaternions used to compose elements of the } \\
\text { rotation matrix }\end{array}$ \\
\hline$F_{x}, F_{y}, F_{z}$ & $\begin{array}{l}\text { resultant force components on the } \mathrm{X}, \mathrm{Y} \text { and } \mathrm{Z} \\
\text { axis [Newtons] }\end{array}$ \\
\hline$p, q, r$ & $\begin{array}{l}\text { angular velocities on the pitch, roll and yaw } \\
\text { axis [radians/second] }\end{array}$ \\
\hline$F_{a, p}$ & $\begin{array}{l}\text { vector sum of propulsive and aerodynamic } \\
\text { forces along the given axis [Newtons] }\end{array}$ \\
\hline$\omega_{x B}^{E}$ & $\begin{array}{l}\text { angular velocity around } \mathrm{x} \text { axis expressed in } \\
\text { Earth reference frame }\end{array}$ \\
\hline$\omega_{y B}^{E}$ & $\begin{array}{l}\text { angular velocity around y axis expressed in } \\
\text { Earth reference frame }\end{array}$ \\
\hline$\omega_{z B}^{E}$ & $\begin{array}{l}\text { angular velocity around } \mathrm{z} \text { axis expressed in } \\
\text { Earth reference frame }\end{array}$ \\
\hline$M$ & rodynamic moment around $\mathrm{x}$ axis \\
\hline
\end{tabular}

Corresponding author: Nicolae Jula, Ph.D., Prof., research field: faculty for electronic and information military systems. E-mail: nicolae.jula@gmail.com.

\begin{tabular}{|c|c|}
\hline$M_{y}$ & aerodynamic moment around y axis \\
\hline$M_{z}$ & aerodynamic moment around $\mathrm{z}$ axis \\
\hline$\rho$ & local air density $\left[\mathrm{kg} / \mathrm{m}^{3}\right]$ \\
\hline$S$ & rocket cross surface $\left[\mathrm{m}^{2}\right]$ \\
\hline$\beta$ & sideslip angle [radians] \\
\hline$\alpha$ & angle of attack [radians] \\
\hline$C_{A}$ & axial force coefficient \\
\hline$C_{y_{\odot}}$ & $\begin{array}{l}\text { side force coefficient derivative with sideslip } \\
\text { angle [1/radian] }\end{array}$ \\
\hline$C_{N \alpha}$ & $\begin{array}{l}\text { normal force coefficient derivative with } \\
\text { angle of attack [1/radian] }\end{array}$ \\
\hline$C_{l}$ & rolling moment coefficient \\
\hline$C_{l p}$ & $\begin{array}{l}\text { rolling moment coefficient derivative with } \\
\text { roll rate }[1 / \text { radian }]\end{array}$ \\
\hline$C_{m \alpha}$ & $\begin{array}{l}\text { pitching moment coefficient derivative with } \\
\text { angle of attack [1/radian] }\end{array}$ \\
\hline$C_{m \alpha}$ & $\begin{array}{l}\text { pitching moment coefficient derivative with } \\
\text { angle of attack rate [1/radian] }\end{array}$ \\
\hline$C_{n r}$ & $\begin{array}{l}\text { yawing moment coefficient derivative with } \\
\text { yaw rate }[1 / \text { radian }]\end{array}$ \\
\hline$C_{m q}$ & $\begin{array}{l}\text { pitching moment coefficient derivative with } \\
\text { pitch rate [ } 1 / \text { radian] }\end{array}$ \\
\hline$C_{n p}$ & $\begin{array}{l}\text { yawing moment coefficient derivative with } \\
\text { pitch rate }[1 / \text { radian }]\end{array}$ \\
\hline$v$ & $\begin{array}{l}\text { total velocity independent of reference frame } \\
\text { [meters/second] }\end{array}$ \\
\hline$L$ & reference length [meters] \\
\hline
\end{tabular}




\section{Introduction}

High altitude balloons are an inexpensive method of reaching altitudes from as low as $10 \mathrm{~km}$ to as high as over $50 \mathrm{~km}$ [1]. Nowadays, two main types of high altitude balloons are used:

- Rigid balloons;

- Flexible latex balloons (e.g.: weather balloons);

Balloons are usually filled with helium or hydrogen which ensures the upward lift force generally decreasing with altitude (Fig. 1).

One of the most used types of balloons is the flexible latex balloons which ensure expansion of the gas inside the balloon as the altitude increases. Upon reaching maximum expandable volume the latex balloon breaks apart and this breaking apart is described in the literature as the burst. After the burst the payload returns to Earth by the means of a recovery parachute that decreases the descent velocity down to acceptable values. A typical descent velocity can be anywhere between $5 \mathrm{~m} / \mathrm{s}$ and $10 \mathrm{~m} / \mathrm{s}$ depending on the type of equipment that the payload consists of. The maximum altitude reached by a high altitude balloon was $53 \mathrm{~km}$ in 2012, reached by BU60-1. This balloon was of rigid type and the envelope was made of a $3.4 \mu \mathrm{m}$ polyethylene film. The BU60-1 balloon was $34.37 \mathrm{~kg}$ in empty weight, $74.5 \mathrm{~m}$ in length, and $53.7 \mathrm{~m}$ in diameter. The total weight including $0.8 \mathrm{~kg}$ of parachute package and $4.6 \mathrm{~kg}$ of observation instruments was $39.77 \mathrm{~kg}$.

\subsection{DOF Payload Numerical Model}

A 6 DOF (degrees of freedom) numerical simulation was developed inhouse and allows to model the attitude of the payload under the various forces that acts on it.

This model is useful whenever one intends to integrate an IMU (inertial navigation unit) on the payload in order to recover attitude and position throughout the flight. The model is based on a general missile code that was developed also in-house [2].

The Earth's diurnal angular velocities are considered

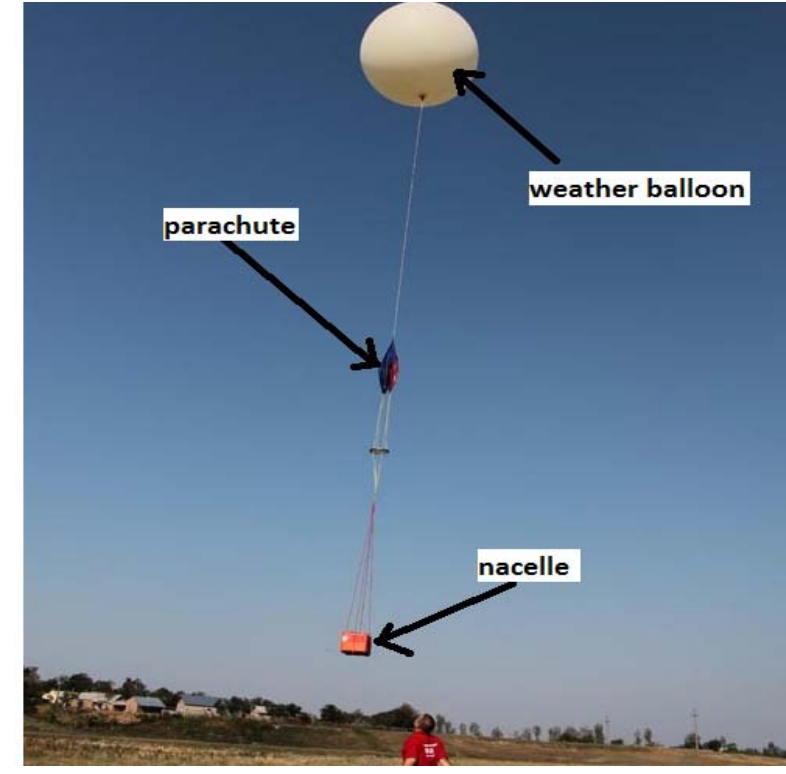

Fig. 1 High altitude balloon flight train.

above basically as transport velocities for the transformation from one frame of reference to another.

Hence, with the above simplifications of non-rotating, flat Earth approximation, the translational equations of motion in tensor notation form become [3]:

$$
m D^{B} v_{B}^{E}+m \Omega^{B E} v_{B}^{E}=F_{a, p}+m g
$$

Eq. (1) can be written in matrix coordinate form which makes them easier to be programmed on a computer [4-8]:

$$
\begin{aligned}
& {\left[\begin{array}{l}
\dot{u} \\
\dot{v} \\
\dot{w}
\end{array}\right]^{B}+\left[\begin{array}{ccc}
0 & -r & q \\
r & 0 & -p \\
-q & p & 0
\end{array}\right]^{B}\left[\begin{array}{c}
u \\
v \\
w
\end{array}\right]^{B}=} \\
& =\left[\begin{array}{l}
F_{x} / m \\
F_{y} / m \\
F_{z} / m
\end{array}\right]^{B}+\left[\begin{array}{lll}
t_{11} & t_{12} & t_{13} \\
t_{21} & t_{22} & t_{23} \\
t_{31} & t_{32} & t_{33}
\end{array}\right]^{B L}\left[\begin{array}{c}
0 \\
0 \\
m g
\end{array}\right]^{L}
\end{aligned}
$$

Eq. (2) gives the translational accelerations in the body reference frame and by double integrating them and rotating to Earth reference frame one can obtain the coordinates of the center of mass of the vehicle.

Next the rotational dynamics equations that provide the relation between the aerodynamic and propulsive moments and angular accelerations of the rocket are shown. Through the double integration of the angular accelerations one can obtain the angular orientation in 
terms of pitch, yaw and roll angles, hence, obtaining the full attitude solution.

By applying Euler's law, the following attitude dynamics equations in the body coordinates frame can be obtained because the moments of inertia tensor has a simple and constant form in this reference system. The attitude dynamics equations in quaternion formulation are as follows (Eq. (3)):

$$
\left[\begin{array}{c}
\dot{q_{0}} \\
\dot{q_{1}} \\
\dot{q_{2}} \\
\dot{q_{3}}
\end{array}\right]=\frac{1}{2}\left[\begin{array}{cccc}
0 & -p & -q & -r \\
p & 0 & r & -q \\
q & -r & 0 & p \\
r & q & -p & 0
\end{array}\right]\left[\begin{array}{c}
q_{0} \\
q_{1} \\
q_{2} \\
q_{3}
\end{array}\right]
$$

The quaternions are related to the Euler angles through the following well-known relations in the aerospace field [4]:

$$
\begin{aligned}
& q_{0}=\cos \left(\frac{\psi}{2}\right) \cos \left(\frac{\theta}{2}\right) \cos \left(\frac{\varphi}{2}\right)+\sin \left(\frac{\psi}{2}\right) \sin \left(\frac{\theta}{2}\right) \sin \left(\frac{\varphi}{2}\right) \\
& q_{1}=\cos \left(\frac{\psi}{2}\right) \cos \left(\frac{\theta}{2}\right) \sin \left(\frac{\varphi}{2}\right)-\sin \left(\frac{\psi}{2}\right) \sin \left(\frac{\theta}{2}\right) \cos \left(\frac{\varphi}{2}\right) \\
& q_{2}=\cos \left(\frac{\psi}{2}\right) \sin \left(\frac{\theta}{2}\right) \cos \left(\frac{\varphi}{2}\right)+\sin \left(\frac{\psi}{2}\right) \cos \left(\frac{\theta}{2}\right) \sin \left(\frac{\varphi}{2}\right) \\
& q_{3}=\sin \left(\frac{\psi}{2}\right) \cos \left(\frac{\theta}{2}\right) \cos \left(\frac{\varphi}{2}\right)-\cos \left(\frac{\psi}{2}\right) \sin \left(\frac{\theta}{2}\right) \sin \left(\frac{\varphi}{2}\right)
\end{aligned}
$$

Based on the above quaternions (Eq. (4)) one can write the full transformation matrix from body to Earth reference frame:

$$
\begin{aligned}
& {[T]^{B L}=} \\
& =\left[\begin{array}{ccc}
q_{0}^{2}+q_{1}^{2}-q_{2}^{2}-q_{3}^{2} & 2\left(q_{1} q_{2}+q_{0} q_{3}\right) & 2\left(q_{1} q_{3}-q_{0} q_{2}\right) \\
2\left(q_{1} q_{2}-q_{0} q_{3}\right) & q_{0}^{2}-q_{1}^{2}+q_{2}^{2}-q_{3}^{2} & 2\left(q_{2} q_{3}+q_{0} q_{1}\right) \\
2\left(q_{1} q_{3}+q_{0} q_{2}\right) & 2\left(q_{2} q_{3}-q_{0} q_{1}\right) & q_{0}^{2}-q_{1}^{2}-q_{2}^{2}+q_{3}^{2}
\end{array}\right] \text { (5) }
\end{aligned}
$$

Next the Euler equations are written in simple scalar form for easier programming on the computer through the following relations:

$$
\begin{aligned}
& \dot{p}=\frac{1}{I_{1}}\left[\left(I_{2}-I_{3}\right) q r+M_{x}\right] \\
& \dot{q}=\frac{1}{I_{2}}\left[\left(I_{3}-I_{1}\right) p r+M_{y}\right] \\
& \dot{r}=\frac{1}{I_{3}}\left[\left(I_{1}-I_{2}\right) p q+M_{z}\right]
\end{aligned}
$$

Eq. (6) represents the components of the angular acceleration along the axis of the body reference frame and by double integrating them one can obtain the attitude angles: pitch, roll, yaw.

The 6 DOF model will be used in implementing an autonomous steerable parachute for the controlled recovery of high altitude balloon payloads. This will ensure the limitation of drift and will decrease the cost of recovery of such payloads. The entire 6 DOF will be coupled with a GPS module that will provide positioning data and drift correction for the MEMS (micro-electro-mechanical systems) inertial sensors of the IMU (inertial measurement unit).

\section{Ascent Dynamics Model}

An important parameter for high altitude flights is the ascent velocity. The ascent velocity is dependent on both the payload mass as well as the general expected flight performances. One example is that the payload is required to have a certain altitude at a certain moment of time. Such an example is represented by ECLIPSER-1 flight which needed to capture the eclipse at $25 \mathrm{~km}$ altitude and, hence, a precise timing had to be taken into account when computing the ascent rate and the time of launch.

A 1-D model that predicts the ascent speed taking into account the atmosphere model, payload characteristics and some aerodynamics forces is developed.

For a payload hanged under a balloon it is possible to write the Eq. (7) of motion on vertical axis as follows:

$$
F_{\text {lift }}-G-\rho v^{2} S C_{x} \frac{1}{2}=0
$$

Hence it is considered that weight $G$, lifting force $\mathrm{F}_{\text {lift }}$ and aerodynamic drag force $D$ are the only forces that act on the balloon on the vertical axis. At equilibrium the ascent velocity is constant and, hence, the resultant of the above forces should be zero.

It is assumed that the gas inside the envelope expands isothermally and hence the authors can write 
the Eq. (8) for the gas expansion during an infinitesimal increase of altitude:

$$
p V=\text { const }
$$

In Eq. (8), $p$ is the local atmospheric pressure which is related to the altitude by the usual barometric relation:

$$
p=p_{0} e^{-\mu g h / k T}
$$

Hence, by Eq. (9), one can obtain the atmospheric pressure at any altitude; this pressure is connected directly to atmospheric density which is a parameter that directly influences the flight dynamics of the vehicle.

Various values for the ascent velocities can be obtained by setting a certain amount of gas for a certain payload and balloon size.

The entire ascent of the balloon can be viewed as the isothermal expansion of the gas bubble represented by the balloon alongside with the dynamics generated by the expanding bubble and decreasing of air density with the increase of altitude.

\section{High Altitude Balloon Missions}

Three missions have been undertaken in order to validate the proposed solution for the payload, flight telemetry equipment as well as general launch procedures. First two flights were launched from Buzău city, Romania (October, 2011 and August, 2012) and represented the preparation for the third flight that took off from Queensland (near Zimba) Australia on November 2012.

In this paper the focus is only on the telemetry data collected during the first flight in Romania. Future papers will be devoted to detailed analysis of the telemetry data of the second flight from Romania and the Australia flight.

Fig. 2, shows the altitude as a function of time for each flight while Fig. 3 shows the trajectory of each mission over the ground.

Hence, it is observed a very good agreement between the predicted ascent speed using the ascent velocity model and the measured ascent velocity for each of the flights.

The horizontal axis in Fig. 2 represents time. A dropout in telemetry data is observed when time reaches the point 270 on the horizontal axis. This was produced by the positioning of the GPS module under a foam layer which in conjunction with the violent rotations of the payload after the burst (visible on the video recording) lead to a temporary loss of GPS signal.

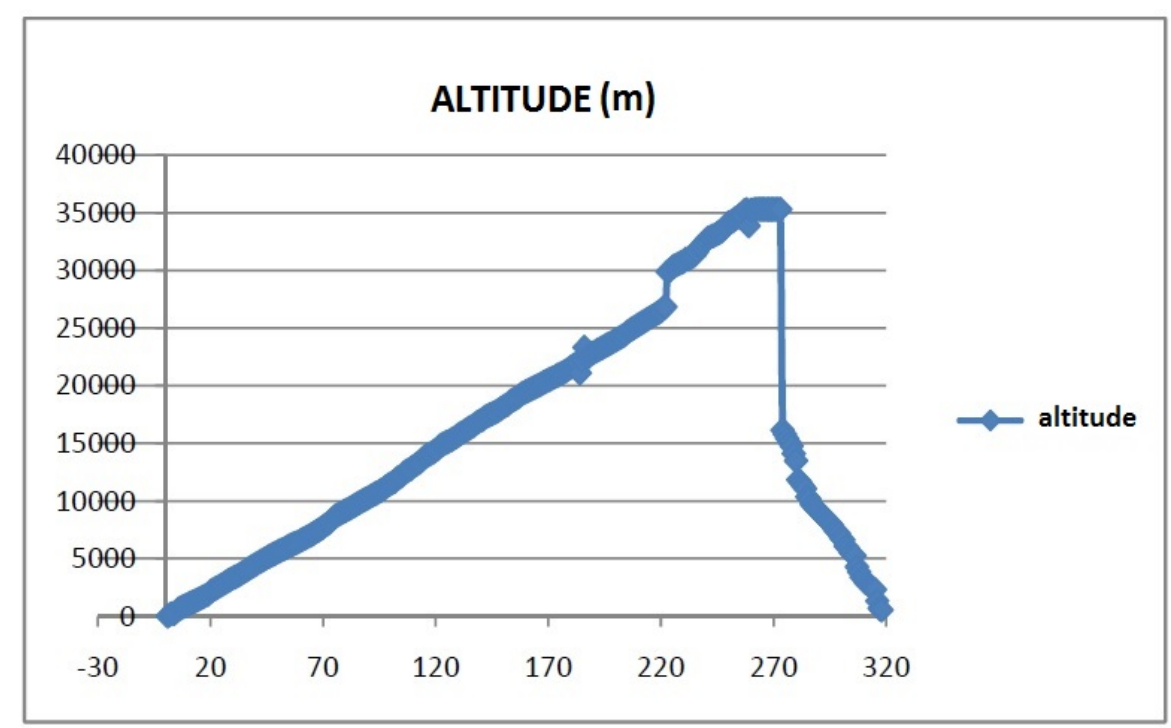

Fig. 2 Variation of altitude with time for stratospherium 1. 


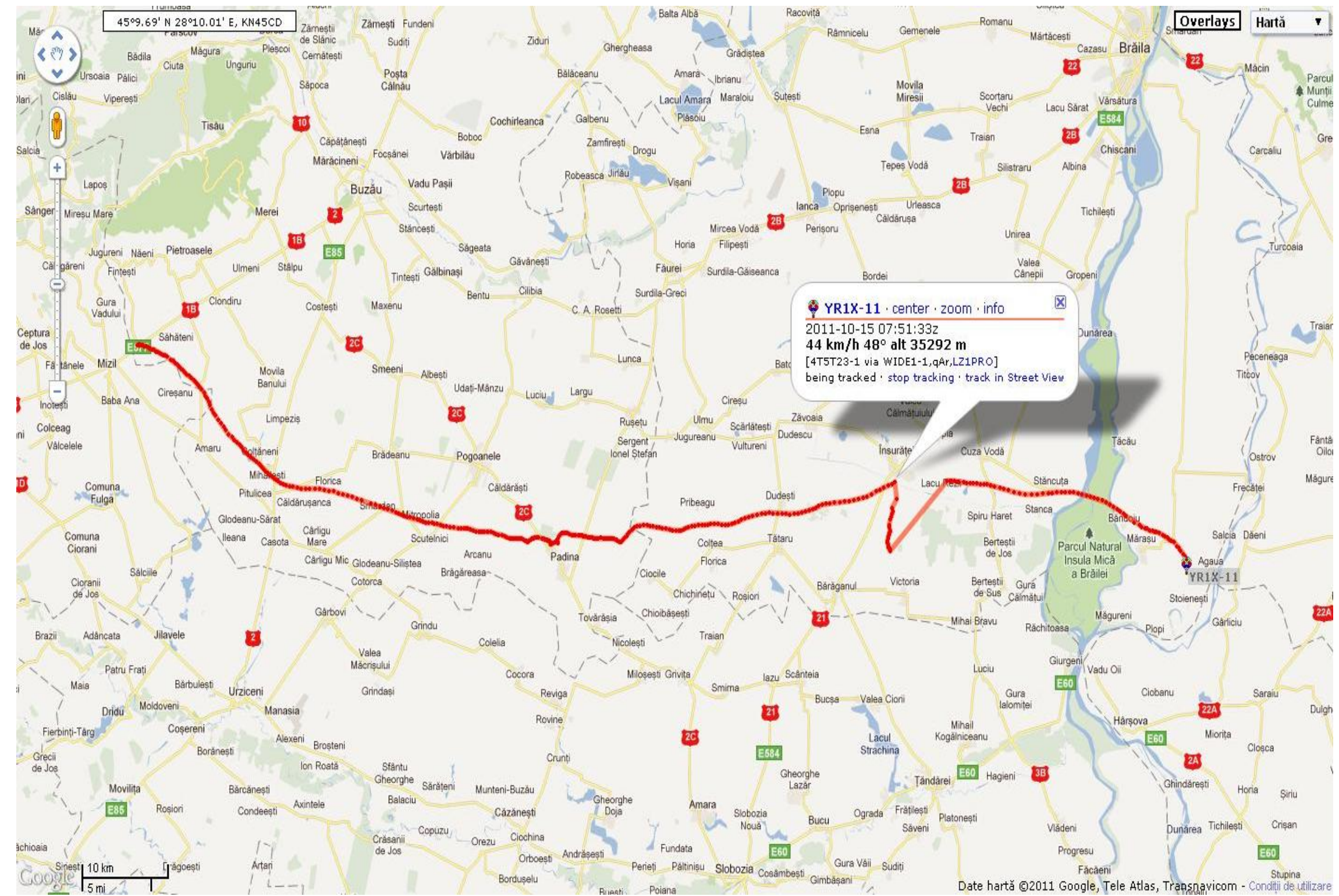

Fig. 3 Trajectory of Stratospherium 1 as received by APRS network. 


\section{Conclusion}

High altitude balloons are an inexpensive method of researching high altitudes and they are available on demand at mostly any point in the world. Satellites are more expensive and their data is not available on demand at anytime, anywhere.

Through this work it is developed an extensive 6 DOF model that allows designing an IMU controller for a steerable parachute in order to reduce drifts on future flights.

A 1D ascent velocity model is developed which ensures the success of even the most difficult and time sensitive flights.

At the same time it is proposed that the platform to be used in calibration and validation of satellite data as well as determining the vertical profile of the atmosphere.

Next work will involve a complete model for the steerable parafoil as well as several test flights to validate the guidance algorithm.

\section{References}

[1] Nayak, A. G., Sreejith, M., and Safonova, J. M. 2013.
"High Altitude Ballooning Program at the Indian Institute for Astrophysics." Current Science 4 (6): 708-13.

[2] Khalil, M., Abdalla, H., and Kamal, O. 2009. "Trajectory Prediction for Typical Fin Stabilized Artillery Rocket.” In Proceedings of the 13th International Conference on Aerospace Sciences and Aviation Technology, Cairo, Egypt.

[3] Pawat, C., Weerawut, C., and Navapan, N. 2011. "A Comparative Study on 6-DOF Trajectory Simulation of a Short Range Rocket Using Aerodynamic Coefficients from Experiments and Missile DATCOM." The Second TSME International Conference on Mechanical Engineering, Krabi, Thailand.

[4] Peter, Z. 2000. "Modelling and Simulation of Aerospace Vehicle Dynamics." AIAA, 2: 20-100.

[5] Florin, M., Lucian, G., Gabriel, M., and Ionut, M. 2014. "Trajectory Modeling of Grad Rocket with Low-Cost Terminal Guidance Upgrade Coupled to Range." Romanian Journal of Physics 59 (3-4): 370-81.

[6] Design of Aerodynamically Stabilized Free Rocket. 1990. "MIL-HDBK-762." US Army Missile Command, AL. USA.

[7] Joseph, D. 2006. "Ballistic Missile Trajectory Estimation." MSc thesis, Naval Postgraduate School Monterey, California.

[8] Dimitrios, N. G. 2008. "A Review of Flight Dynamic Simulation Model of Missiles" 2nd European Computing Conference, Malta. 